\title{
Comparison of the Measuring Devices during the Evaluating of Circularity Deviation
}

\author{
Robert Čep ${ }^{1, *}$, Šárka Malotová ${ }^{1}$, Vladimír Vrba ${ }^{1}$
}

1 Department of Machining, Assembly and Engineering Metrology, Faculty of Mechanical Engineering, V̌̌B-TU 0strava, 17. listopadu 15/2172, 0stravaPoruba, 70833, Czech Republic

\begin{abstract}
The contribution deals with the comparison of devices for measuring and evaluation of circularity of deviation. The circularity of deviation was measure on the specific component using in practice. The deviation was measured with using standard circular gauge Formtester MMQ 44 CNC and 3D measuring device SCAN Max. The results were statistical evaluated in tables. Part of the results is the technical and economic evaluation too.
\end{abstract}

Keywords: metrology, circularity deviation, 3D device, measurement.

\section{Introduction}

The main aim of machining process is production removable components with maximum functionality and adequately costs. Each part needs accuracy production with predefined dimensions, geometry and surface adjustment. With development more accuracy machine tools are allowed to make very small components in tolerances. Geometrical specification of component in engineering and metrology are essential for proper assembly and safety of manufactured parts. All of them have cylindrical and circular shape and control is necessary for safety state of all system. The tolerances of shape (e.g. circularity) are checked with using 3D measuring machine and devices, which allow repeatability, accuracy and reliability of measuring. [1, 2]

The circularity deviation is defined by standard ČSN EN ISO 1101 - Geometrical specification of components - geometrical tolerance - The tolerance of shape, orientation, location and throwing. Real surfaces show deviation given nominal values. In this tolerance field must be the actual element. The circularity deviation is the biggest perpendicular distance, which is measured to envelope circle (see fig. 1). Circularity deviations are measured with special touch device, which rotates around fixed component, respectively conversely or used CMM. The circularity deviation $(\Delta)$ of points of actual profile of enveloping circle is the biggest distance. These deviations together with surface roughness significantly influence the level of vibration of rotating parts, hence they need to be properly diagnosed and improving the whole process of production. (Figure 1) [3]

\section{Check selected component}

The checked component is part of system using in automobile SCANIA P420/ R420 into motor part - pulley (figure 2). The component was machined and then quenching into a salt bath. Then component was moved to laboratory of metrology, where was measured tolerances include circularity deviation. The nominal value of ring was $\varnothing 15 \mathrm{~mm}$. The control of circularity was measured with 


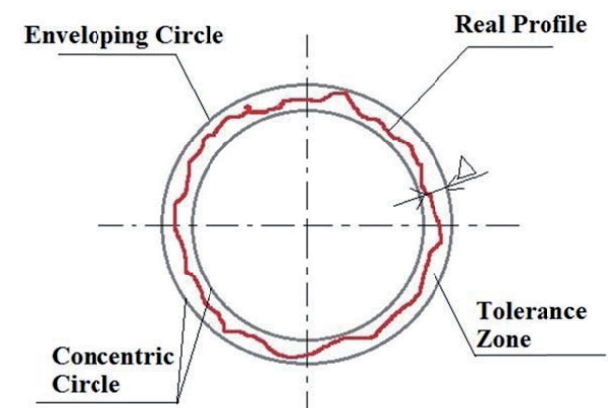

Fig. 1: Circularity deviation [1].
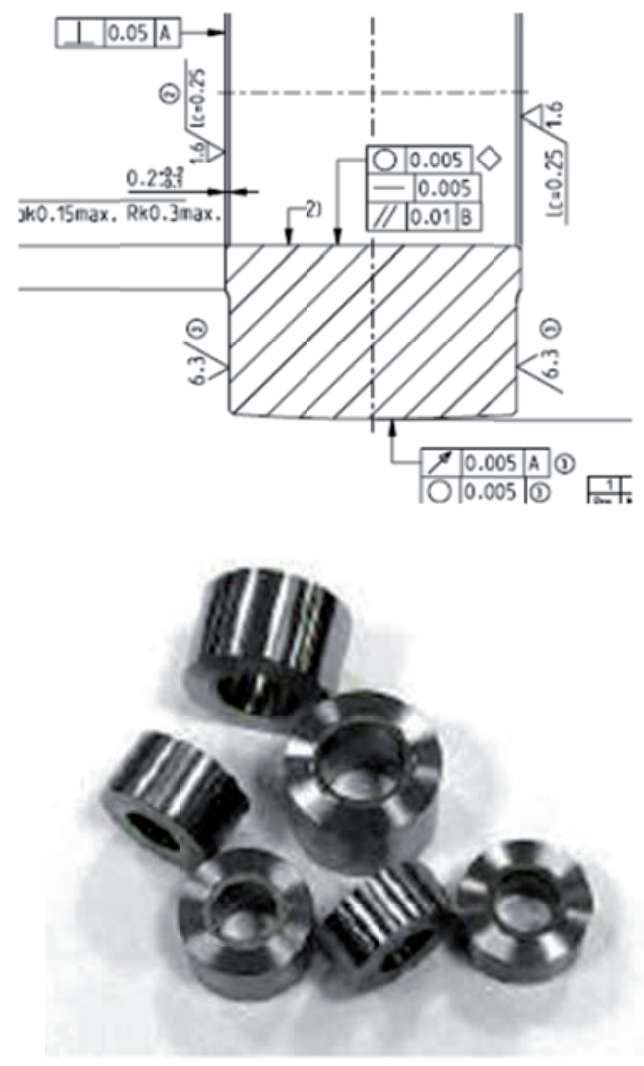

Fig. 2: Measured component [4].

using circular gauge Formtester MMQ 44 CNC and 3D measurement device SCAN Max. [4]

Deviation was measured with using standard circular gauge Formtester MMQ 44 CNC on principle Least squares method (LSC). Before the measuring was created working operation. The component was fixed into chuck and measured by the ball arm. It is very accuracy device for checking of deviation of shape and location according to standard ČSN EN ISO 1101. The device is composed from sliding arm, measuring range $(X-Z: 180-500) \mathrm{mm}$, rotary table, measuring touch rotatable around the $360^{\circ}$ axis and PC with software (figure 3 ). This device offers double the accuracy in roundness measurements, improved straightness measurements, and faster measuring speeds. The system will measure parts up to $620 \mathrm{~mm}$ in diameter and $640 \mathrm{~mm}$ in height. [5]

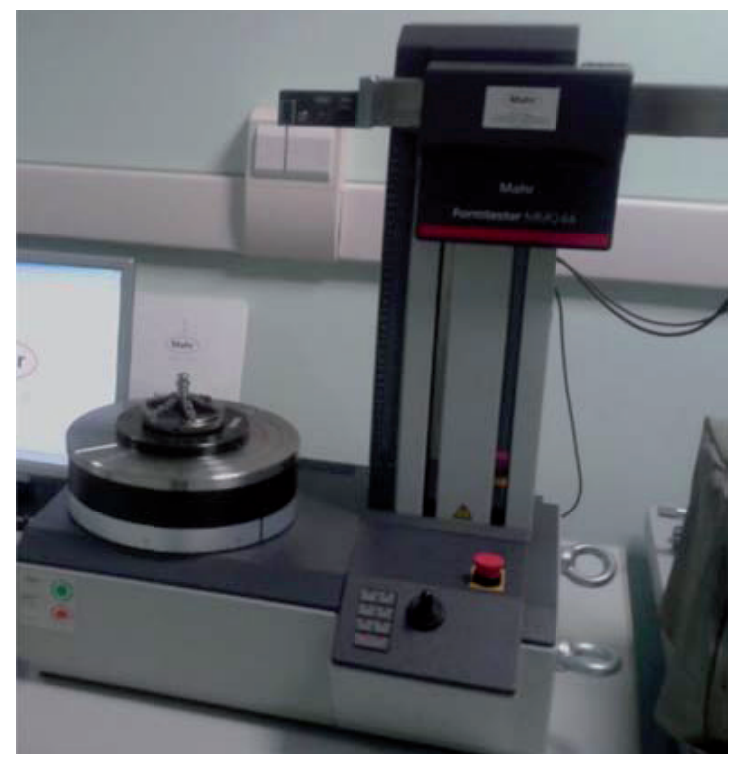

Fig. 3: Formtester MMQ 44 CNC [5].

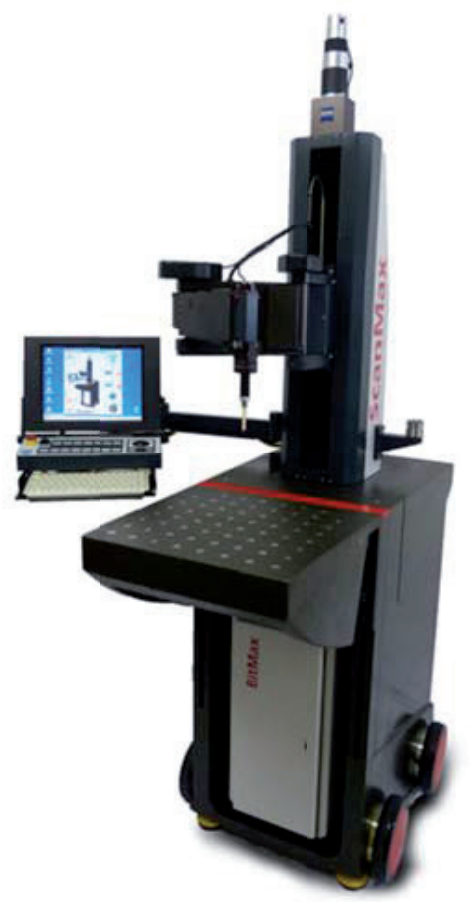

Fig. 4: SCAN Max - 3D device [6]. 
Then the circularity deviation was measured wit using SCAN Max 3D device (figure 4). SCAN Max is Carl Zeiss Coordinate Measurement Machine (CMM). Partially manual control along with active scanning means high precision combined with ease of use. SCAN Max is extremely small in relation to its wide range of applications and can be easily placed out of the workshop. It has Scan Ware operating system with ball probes with diameters 2, 3, 5, 8mm, plate diameter $15 \mathrm{~mm}$ and thickness $1 \mathrm{~mm}, 3 \mathrm{~mm}$ diameter

Tab. 1: Measured values. roller probe. Measuring range is $(850 \times 450 \times 450)$ $\mathrm{mm}$. The both measurement processed under metrological conditions in accredited laboratories.

\section{Measured values}

The measuring of circularity of deviation (LSC) proceeded under constant conditions - ambient temperature $20,1^{\circ} \mathrm{C}$ and number of measuring was thirty. The results were took into table 1 and then was evaluated uncertainty type A and B.

For calculation of standard uncertainty of type $B$, was took into the expanded uncertainties of

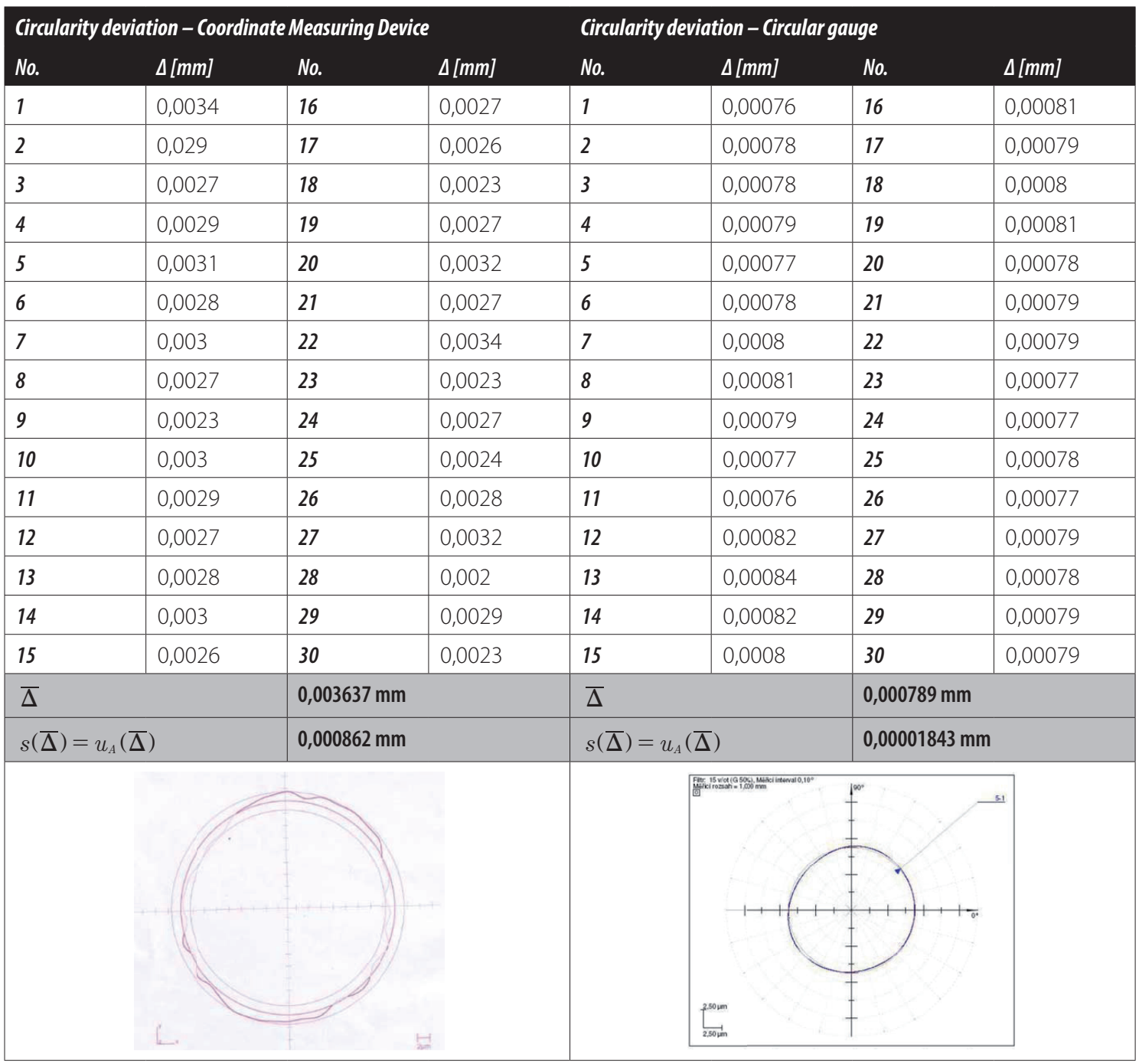

the $3 \mathrm{D}$ device and temperature correction $\delta \mathrm{T}$. The temperature deviation of measuring component from the ambient temperature stayed $\pm 0,2 \mathrm{~K}$. The ambient temperature in laboratory was $\pm 0,5 \mathrm{~K}$. We did not take into the influence of uncertainty of ring. Temperature influences of laboratory $\delta T_{A}$ and ring $\delta T_{x}$ was ignored due to very low values. The results of measurement are shown in table 2 . 
Tab. 2: Results of measurement.

\begin{tabular}{|c|c|c|c|}
\hline \multicolumn{2}{|l|}{ Quantity } & \multirow{2}{*}{$\begin{array}{l}\text { Circularity deviation - Coordinate Measuring Device } \\
\text { insignificant }\end{array}$} & \multirow{2}{*}{$\begin{array}{l}\text { Circularity deviation - Circular gauge } \\
\text { insignificant }\end{array}$} \\
\hline Laboratory & $\delta T_{A}$ & & \\
\hline Bearing ring & $\delta T_{x}$ & insignificant & insignificant \\
\hline Temperature correction & $\delta T$ & insignificant & insignificant \\
\hline Uncertainty of device & $\delta T_{i}$ & $1,7 \mu \mathrm{m}$ & $0,16 \mu \mathrm{m}$ \\
\hline Total uncertainty & Uв & $1,7 \mu \mathrm{m}$ & $0,16 \mu \mathrm{m}$ \\
\hline Combined uncertainty & $\mathrm{uc}_{\mathrm{c}}$ & $1,7 \mu \mathrm{m}$ & $0,16 \mu \mathrm{m}$ \\
\hline Extended uncertainty & U & $3,4 \mu \mathrm{m}$ & $0,32 \mu \mathrm{m}$ \\
\hline Results of measurement & $\Delta$ & $(0,00364 \pm 0,00340) \mathrm{mm}$ & $(0,00079 \pm 0,00032) \mathrm{mm}$ \\
\hline Tolerance $\pm 0,005 \mathrm{~mm}$ & & UNSUITABLE & SUITABLE \\
\hline
\end{tabular}

The steel ring was measured thirty times by the both devices and statistically evaluated. The circular gauge was suitable and satisfied the allowed tolerance.

\section{Technical and economic evaluation - conclusion}

From the calculations it can be stated that the 3D device SCAN Max is only measuring instrument and in comparison with laboratory circular gauge Formtester MMQ 44 CNC, which is used for measuring of deviations of shape a location and its accuracy is higher than 3D device SCAN Max. But in our condition where is tolerance $\pm 50 \mu \mathrm{m}$ we could use 3D device for control the circularity of deviation, because it is only inter-operational control. Determination of time saving was calculated on the principle of number seven orders of 2 pieces per one work shift. In table 3, there is show time savings for devices.

The aim of the work was to compare measuring device during evaluation of circularity deviation of selected components from practice. The measuring devices were circular gauge Formtester MMQ 44 CNC and 3D measuring device SCAN Max, which are used in workroom like a measuring instrument. For the conditions in workroom and inter-operational control, they could use less accuracy device, because the component will be futher machined and on the economic page it is better to use 3D device.

Tab. 3: Time saving.

\begin{tabular}{|l|l|l|l|l|} 
Device & $\begin{array}{l}\text { Number of } \\
\text { samples } \\
\text { per 1 work } \\
\text { shift [ks] }\end{array}$ & $\begin{array}{l}\text { Number of } \\
\text { standard } \\
\text { minute per } \\
\text { 1 sample } \\
\text { [Nmin] }\end{array}$ & $\begin{array}{l}\text { Number of } \\
\text { standard } \\
\text { min per } \\
\text { 1 day } \\
\text { [Nmin/ } \\
\text { day] }\end{array}$ & $\begin{array}{l}\text { Time } \\
\text { savings } \\
\text { for 1 year } \\
\text { [day]- } \\
\text { 3D device }\end{array}$ \\
\cline { 1 - 3 } 3D device & 14 & 6 & 84 & \multirow{2}{*}{9,52} \\
\hline $\begin{array}{l}\text { Circular } \\
\text { gauge }\end{array}$ & 14 & 10 & 140 & \\
\hline $\begin{array}{l}\text { Time saving with using 3D device for measuring and } \\
\text { evaluation of circularity deviation was 9.5 days. }\end{array}$
\end{tabular}

Tab. 4: Financial saving.

\begin{tabular}{|c|c|c|c|c|c|}
\hline Device & $\begin{array}{l}\text { Number of samples } \\
\text { per } 1 \text { work shift [ks] }\end{array}$ & Hour rate [KČ] & Kč per work shift [Kč] & $\begin{array}{l}\text { Financial savings } \\
\text { for } 1 \text { day }[K C ̌]-3 D \\
\text { device }\end{array}$ & $\begin{array}{l}\text { Financial savings } \\
\text { for } 1 \text { year }[K(K \bar{C}]-3 D \\
\text { device }\end{array}$ \\
\hline 3D device & 14 & 120 & 168 & \multirow{2}{*}{205,33} & \multirow{2}{*}{50305,85} \\
\hline Circular gauge & 14 & 160 & 373,33 & & \\
\hline
\end{tabular}




\section{References and Notes}

[1] ČSN ISO 230 - 4. Test code for machine tools - Part 4: Circular tests for numerically controlled mach. Czech standard. 2010.

[2] Technical drawings - Geometrical Tolerancing, ISO 1101, (1983)12-01

[3] SOUZA, C.C. at al. A CONTRIBUTION TO THE MEASUREMENT OF CIRCULARITY AND CYLINDRICITY DEVIATIONS. Brazilian Congress of Mechanical Engineering. Brazil, 2011, (21), 791 800.

[4] IRIŠEK, D. Roudness Measuring at Coordinating Measuring Machines. Ostrava: Department of Working and Assembly, Faculty of Mechanical Engineering, VŠB-Technical University of Ostrava, 2009, 42 s. Thesis head: Vrba Vladimír.

[5] Mahr Federal Introduces New And Improved Formtester. Metrology World.com [online]. 2005 [cit. 2017-07-26]. Available from: https://www.metrologyworld.com/doc/mahrfederal-introduces-new-and-improved-form-0001

[6] Zeiss, Carl. Scanmax and probe. Available from: http://www. ufix.se/scanmax.html.

\section{Biographical notes}

Assoc. Prof. Robert Čep, Ph.D., MSc. (born 1977) got the title at VSBTechnical University of Ostrava in field Mechanical Engineering. He specializes about machining and engineering metrology. Currently, he is vice-dean for PhD studium, external workplaces and personal development. He deals with machining and its optimalization, testing of cutting tools, surface integrity and measuring accuracy of machine tools. Šárka Malotová, MSc. (born 1990) is Ph.D. student at Dpt. Machining, Assembly and Engineering Metrology. She deals with measuring of surface topography and testing of cutting tool. Her dissertation thesis is about the evaluation of durability of cutting tools during parting-off of stainless steels. Assoc. Prof. Vladimír Vrba, CSC, MSc. is emeritus professor at pt. Machining, Assembly and Engineering Metrology. His field is Engineering Metrology. 